\title{
Identification of Critical Thinking Process in Solving Mathematic Problems
}

\author{
Sutini ${ }^{1,}$ Akbar Sutawidjaja ${ }^{2}$ I. Nengah Parta ${ }^{2}$, \\ Hery Susanto ${ }^{2}$ \\ (Mathematics Education, Islamic State University of Surabaya) ${ }^{l}$ \\ (Mathematics Education, State University of Malang) ${ }^{2}$
}

\begin{abstract}
Critical thinking skills are very important in everyday life, because critical thinking skills can develop thinking skills, such as the ability to make decisions and solve problems. The purpose of this research is to describe the students' critical thinking process in solving math problems. Critical thinking process in this study refers to the four stages of gathering information, evaluates of information, making solution, and evaluates the Conclusions. In each stage covers various aspects that is at the stage of gathering information includes identifying all of the information, connect the relevant information, grouping information in accordance with sections each - each, and set goals that are asked in the problem based on the information. Stages of evaluates of information include Selecting all information is important, establishing the assumptions of the information in the problem, linking important matters of information based on assumptions and identifying possible strategies to solve the problem. The making solution stage involves predicting the completion steps that are from the information, and processing the completion steps, and establishing the completion result. Stages evaluates the conclusions include Establishing confidence of problem solving outcome, and clarifying problem solving results. This research is a qualitative case study strategy and research place in SMP Negeri 1 Gresik. The material used is a daily problem. To analyze the process of students' critical thinking in solving. The results show that the student performs the complete critical thinking process in solving the problem. But experiencing the error of selecting information caused in the processing of information S1 experiencing misunderstanding and recall the semantic memory. And SI conducts critical thinking process through four stages: gathering information, evaluates of information, making solution, and evaluates the conclusions is complete but experiencing divided attention in setting assumption. Keywords: Critical thinking process and mathematic problems
\end{abstract}

\section{Introduction}

The purpose of learning mathematics is given in schools is to equip students with logical, analytical, systematic, critical, and creative thinking skills, as well as the ability to work together. Such competencies are necessary for students to have the ability to acquire, manage, and utilize information to survive in an everchanging, uncertain and competitive state. It is also intended to develop math skills in problem solving and communicate ideas or ideas using symbols, tables, diagrams, and other media (BNSP, 2006). The ability to think critically is very important in everyday life, because the ability to think critically can develop other thinking skills, such as the ability to make decisions and solve problems. Competence of critical thinking and problem solving are two competencies of several competencies that are emphasized in the 2013 curriculum for mathematics courses in schools.

Solso (1995) the ability to think critically is a process in which new mental representations are formed through information transformation with complex interactions of mental attributes such as judgment, abstraction, logic, imagination, and problem solving. Then Beyer (1985) says that the ability to think critically is the ability to determine the credibility of a source, distinguish between relevant and irrelevant, distinguish fact from assessment, identify and evaluate unspoken assumptions, identify existing biases, identify points of view, and evaluate Evidence offered to support recognition.Patrick (2009) critical thinking is a skill that must be owned by students, academics and those who work to achieve important goals. Later in the research Einav Aizikovitsh-Udi (2003) proved that students develop critical thinking in the teaching of mathematics (probability) so that students can seek truth, open minded and confident. Then Jacob and Sam (2008) define the four stages of the process of critical thinking, namely Clarification, assessment, inference, and strategy. In measuring the ability of students' critical thinking process through the four stages. Then Learning Development Plymouth University (2010), said critical thinking means asking questions to find evidence and good reason before believing something to come true. It begins with stage descriptions, analysis and evaluation.

Schafersman, S.D. (1991), Critical thinking is the right thinking in order to know the relevant and reliable about the world. Critical thinking is thinking reasoning, reflecting, responsible, thinking ability, focused 
on making decisions about what is believed or what needs to be done. Critical thinking is to think of asking the right questions, collecting relevant information, sorting information efficiently and creatively, logically reasoning, to the point of reliable and reliable conclusions. Polya (1973), distinguishes the problem in mathematics into two namely: - Problems to discover, can be theoretical or practical, abstract or concrete, including puzzles. The main part of the problem is about what to look for, what to know, and how to condition it. - Problems to prove, that is a problem to show that a statement is true or false or may not be both. The main part of this type of problem is the hypothesis and conclusion of a theorem that must be verified.

From the results of the study, there are several findings, among others: critical thinking is more studied in the literature review so it has not done field research, measure and develop critical thinking in online discussion forum by filling out research quizoner and interview. As well as measure the ability Critical thinking make use four stages of clarification, assessment, inference, and strategy. So that researchers adapt and collaborate critical thinking process through four stages of gathering information, evaluates of information, making solution, and evaluates the conclusions. In this case researchers want to know what has been done by students in solving the problem. From the results of the settlement will be analyzed and in the know aspects of what has been done by students and who have not done. Because by expressing the critical thinking process of students in solving the problems of mathematics will be obtained a lot of information about the activities of thinking deep, comprehensive, argumentative, logical, and evaluative so as to contribute to the development of mathematics.

Description of the process of critical thinking in solving mathematical problems.

In this study, students are given mathematics about everyday problems with many solutions depending on the students are able to select the information contained in the problem. Students in solving this problem by voicing all that is being thought of (think aloud). Researchers analyze the work and the results of think aloud students then identify the critical thinking process that has been done in solving the math problem.

The process of critical thinking in this study includes math problems, students, gathering information, evaluates of information, making solutions, and evaluates the conclusions, mathematical problem solving. Selecting the information in question. In this case the students in solving the problem have problems in selecting information that made important things to be used to solve the problem. This means that in the gathering information stage the student should really focus on the information contained in the problem including identifying all the information, linking the relevant information, grouping the information according to their respective sections, and setting the objectives in question based on the information. Then the evaluates of information phase includes students selecting all the information into important things, establishing the assumptions of the information in the problem, linking the essentials of the information based on assumptions and identifying possible strategies to resolve the problem. The making solution stage involves students predicting the completion steps that are from the information, and processing the completion steps, and determining the outcome of completion. Stages evaluates the conclusions include Establishing confidence of problem solving outcome, and clarifying problem solving.

\section{Research Methods}

This research is a qualitative research with case study strategy. The research instrument consists of researcher, duty sheet, work result, thought aloud result and interview result. The work and the results of think aloud are all activities that students do when solving the problem. Interview result is interview conducted by researcher to get deeper information. The task sheet instrument in this study is as follows,

Melani's birthday party supplied 69 plates of dishes, the cuisine menu consisted of chicken, rice, and vegetables. Each one chicken plate is reserved for 2 guests, one rice plate is reserved for 3 guests, and one vegetable plate is reserved for 4 guests. At that time Melani's parents paid Rp.80.000,00 / package on the catering party. Most guest Determine which may be present and be able to eat all the dishes based on existing inventory! (Write down the answers and reason). (Each pack consists ofone plate chicken dish, one dish of rice dishes and one dish vegetable dish).

Exposure of research data subject 1 (S1)

\section{Result and Discussion}

$\mathrm{S} 1$ was given problems then $\mathrm{S} 1$ doing problem solving process by voicing what is being thought (think aloud) while structuring information and interview. S1 is a student of grade VIII and S1 completed the problem given during 37: 36 ': 12' '. S1 starts by reading in the heart and watching the problem in silence for a while. In this case S1 reads aloud, while raising the problem sheet. Then at the Gathering Information stage it identifies all the information in the problem, When identifying all the information that is in the problem, S1 mentions all 
the information that is in the problem. Then $\mathrm{S} 1$ uses the bolpoint while pointing and circling the parts in the problem. Then connect the relevant information. At the time of S1 linking relevant information, S1 mentions relevant information in the matter. Then it shows the following think aloud S1, "there is a birthday party, sixtynine dishes, sixty-nine dishes, chicken, rice, and vegetables". Then group the information according to their respective parts. At the time of grouping information, S1 mentions while writing based on the dish menu on the left, and the right many sections for guests. This is shown following results S1 think aloud, "one of two guest reserved chicken dish, a plate of rice earmarked three guests, one vegetable dish reserved four guests. Per package contents one chicken dish, a plate of rice and a vegetable dish. Then set goals that are in trouble. At the time of S1 set goals in the problem based on the information, S1 mention of which will be completed with a loud voice and nodded heads pointing pen to task sheet. Then S1 reads with a nod of his head. This is shown the result of the following $\mathrm{S} 1$ interview,

\section{Q: What have you asked in the problem?}

\section{S1: Asked what most guests who might be coming}

Next stage of Evaluates of Information, S1 selection of information becomes important. When selecting important information, S1 mentions and writes important information. This is shown by the following think aloud S1, "one chicken plate is reserved for two guests, one plate of rice is reserved for three guests, one vegetable plate is reserved for four guests. Per package contents one chicken dish, a plate of rice and a vegetable dish. The party provided sixty-nine dishes. Then set the assumptions of the information. When establishing the assumption of information, $\mathrm{S} 1$ mentions information-based assumptions.

Then S1 mentions by using another way. And then linking information based on assumptions. When connecting important information based on assumptions, S1 mentions the relationship of information based on assumptions. This is shown the results of think aloud S1 says "for example sixty nine dishes of khan dish there is chicken there is rice and vegetables, there are three ........... for three course, sixty nine divided by three, there are twentythree. ... for three, sixty-nine divided by three, twenty-three ". Then identify the strategy to be done. At the time of identifying the strategy undertaken, S1 mentions the strategy to be carried out while confused and speaks for itself. Next S1 mentions by using another way. Next S1 mentions and writes a strategy by trial-and-error by using the Smallest Commonwealth Multiplier.

The next stage in predicting step Making Solution - step completion of the information. At the moment of predicting the steps, S1 mentions possible completion steps in another way. This is shown by the results of think aloud S1 says "if for example this is a chicken plate for two guests, one plate of rice for three guests, and one vegetable plate for four guests ....... if for example twenty-three ........ twenty-three ... twenty-three later if multiplied by forty-six, sixty-nine, the remaining ninety-two lots. " Then processing steps - steps to resolve. Upon completion of the completion steps, S1 mentions clear and ordered completion steps. S1 counts repeatedly and writes results. Then S1 tried to count other paper. S1 performs repeatedly until it gets sixty-three guests with circled marks. At the time of S1 process completion steps, S1 mentions how to use the Commission but experienced confusion while holding his head. Then set the completion result. At the time of setting out the result, S1 mentions the completion result. Then S1 think (while playing bolpoint) what has been written. Then S1 mentions the result of the settlement while holding his head thinking again by talking to himself. Then indicated by structuring the information as follows,

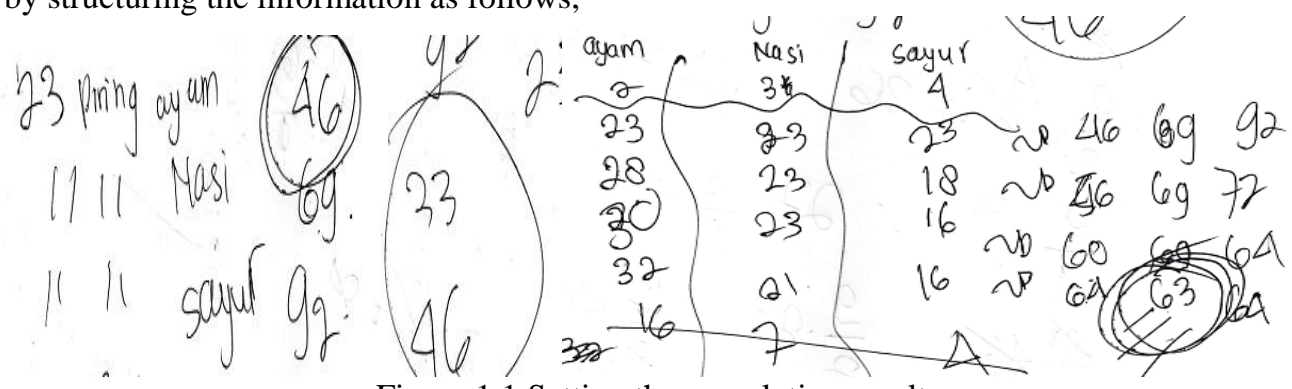

Figure 1.1 Setting the completion result

The next stage of Evaluates the Conclusions in determining the confidence of the outcome of the problem. At the time S1 establishes confidence, S1 mentions the outcome. This can be seen when S1 says that "every guest enjoying all the dishes means only forty-six dong". Then S1 sets the second belief, S1 mentions while pointing the result of completion. This is indicated by the following S1 interview,

Q: How can you be sure of your answer?

S1: I'm sure bu

Then clarify the settlement result. At the time of clarifying the results of problem solving, S1 mentions and circles the number forty-six as a reinforcement when the most guests present are forty-six. Then S1 mentioned the completion result was sixty three guests. This is shown by the result of the interview of S1 as follows, 
Q: How do you reexamine the results of the settlement that has been obtained is correct? S1: because in the way that was past twenty-three I finally tried - it could not finally happen like this sixty-three, forty-six the rest and I checked it we can see from here (pointing at the answer sheet) of the other sixty-three sixty-four. Sixty-four while on the condition that every guest should be able to taste all the dishes so if there are sixty four who do not get the rice. One chicken plate for two guests khan it takes thirty two dishes, one plate of rice for three guests there are twenty one dishes and Vegetable plate vegetable for four guests there were sixteen plates in total all his plate sixty nine dish dishes.

Based on the description of critical thinking process $\mathrm{S} 1$ above, can be described a process of critical thinking S1 in solving mathematical problems as in Figure 1.1 and then diagram image Research problem structure that has been made by researchers, in Figure 1.2 as follows,

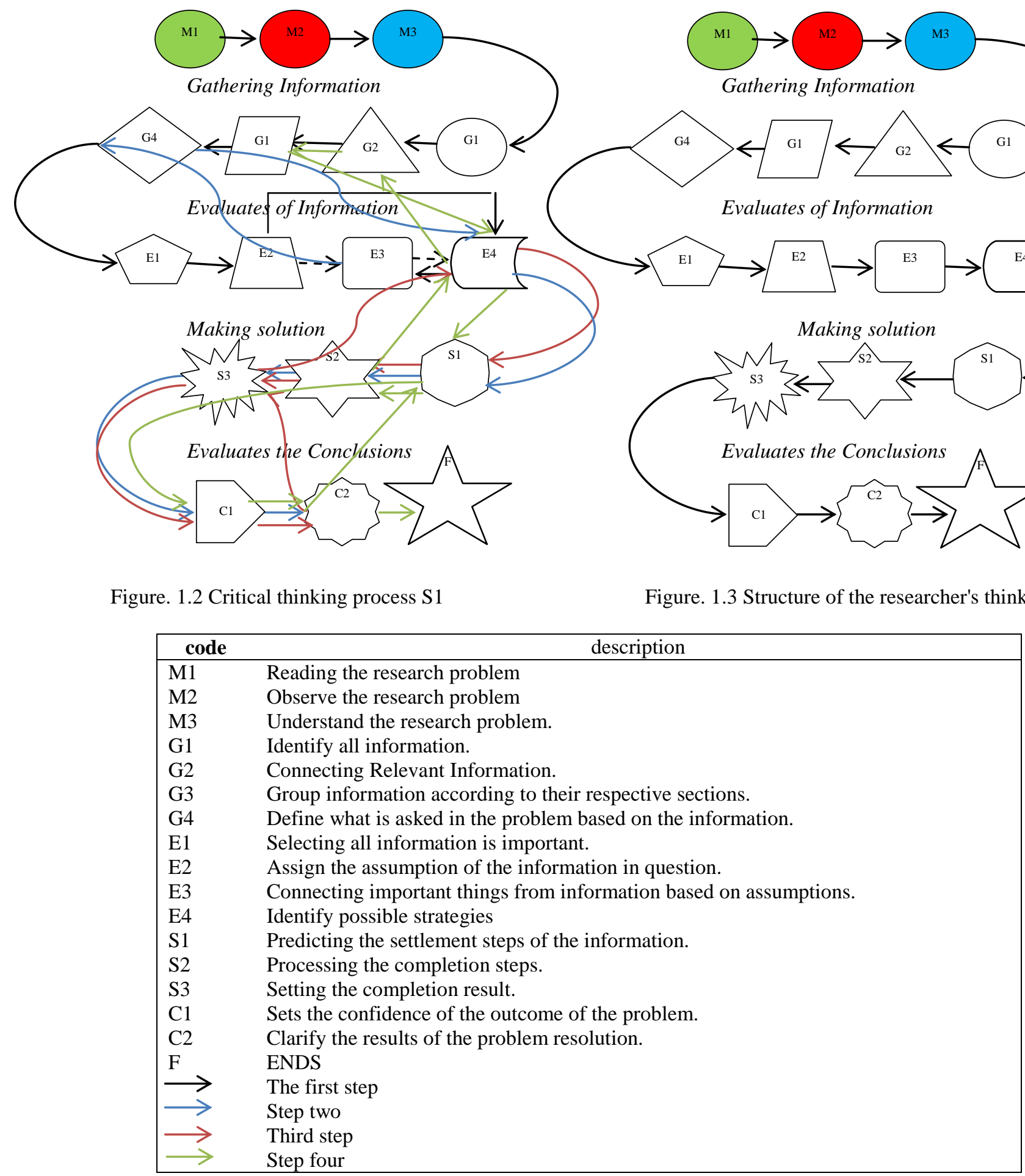


Based on the thought process $\mathrm{S} 1$, indicated S1 S1 perform critical thinking is stuck in the election despite the irrelevant information. This happens because the $\mathrm{S} 1$ considers that information on Perpaket price paid parental Melani Rp. 80.000,00. Each package consists of a plate of chicken, a plate of rice, a vegetable dish is important information.

The discussion of this research is focused on the research question is how the critical thinking process of students in solving mathematical problems. Critical thinking process in this research through four stages: gathering information, evaluates of information, making solution, and evaluates the Conclusions. The findings of this study, the subject of selecting information to experience error. In this case the subject mentions irrelevant information that is the price per package of Rp.80.000,00. Each package consists of one plate of chicken one plate of rice and one vegetable plate. The subject should be able to select the information becomes important that is provided sixty-nine dishes. Each one rice plate for two guests, one rice plate for three guests, and one vegetable plate for four guests. This happens on the subject mentions Perpaket consists of a plate of rice, a chicken dish and a vegetable dish. Then to make sure what he sets S1 mentions and counts until the completion results. After that $\mathrm{S} 1$ feel there is less convinced with the settlement. Then S1 make the second assumption is based number plate is not the same for each menu dishes and minimize residual and guests can enjoy all the menu dishes.

From the findings associated with the process of information processing theory to obtain information, process information, store information, and recall information that is controlled by the brain. S1 mention one chicken dish reserved two guests, a plate of rice earmarked three guests, one vegetable dish reserved four guests. Per package contents one chicken dish, a plate of rice and a vegetable dish. At the party provided sixty-nine plate dish. But S1 that parents Melani pay per package of Rp.80.000,00 for each package consists of a plate of rice, a vegetable dish and a vegetable dish. The same thing is also shown S1 mention that how much money should be paid or incurred parents melani to the catering.

According to Slavin (2006), at the time S1 was given the problem was done sensing registers to the problem. It turns out that S1 gives attention to all information through identifying all the information in the problem. Then transferred to the second component of short-term memory, the subject of selecting the stored information, then recurring so that it is stored in long-term memory in semantic memory. According to Gagne, this happens because S1 has an error when processing information is the stage of motivation, understanding, acquisition, storage, and rethought. Subjects motivate themselves in order to solve the problem correctly. Subsequently the Subject should pay attention to the essential parts of the given problem. So it can select the information properly, and can be stored in the box, then remembered to resolve the problem. In this case S1 assume that Per package consists of one plate of chicken, one plate of rice and one vegetable plate is important information because according to $\mathrm{S} 1$ the reason given is so that parents do not pay or spend a lot of money. Here the understanding of S1 has not been able to focus attention on important information, S1 only understand, but can not get relevant information, so that experience error of selecting information. Then S1 in the stages of recalling the experience or information that has been in store in LTM have errors. It is shown S1 mentioning Melani's parents pay per package of Rp.80.000,00 for each package consisting of one plate of rice, one vegetable plate, and one vegetable plate. So the experience that dingat S1 that ordering food at Melani's birthday party the number of the menu is the same.

Subsequent findings S1 makes two different assumptions. If related to attention or attention done S1 there are two different attention that has been made S1. This is done S1, according to S1 focusing on two information that is considered important. The first concern centered on sixty-nine. Each one chicken plate is reserved for two guests, one serving of vegetables for three guests, and one vegetable plate for four guests per package consisting of one chicken plate, one rice plate and one vegetable plate. So S1 makes the first assumption that many of the attendees will be calculated on a per-package basis purchased by Melani's parents and can enjoy all the menu dishes. Then the second concern on the information that counts the number of dishes dishes sixty nine. Each one chicken plate is reserved for two guests, one serving of vegetables for three guests, and one vegetable plate for four guests. So S1 makes a second assumption that many of the attendees will be counted based on the number of dishes not the same as each menu and can enjoy all the menu dishes. From the explanation, looks S1 when receiving information. S1 experienced concentrated attention shared, the first of the parents Melani pay per package of Rp.80.000,00. Each package consists of one chicken plate, one rice plate and one vegetable plate. And the second is the number of sixty-nine dishes. Then Each one chicken plate is reserved for two guests, a vegetable plate is reserved for three guests, and one vegetable plate is reserved for four guests.

Then the researcher asked the S1, why make two assumptions? According to the explanation S1, the assumption of the first according to the package according to S1 is easier to calculate and the parents Melani fewer orders per package that is only twenty three packages, but then S1 explained that based on the package will be a lot of food the remaining. This happens because the perception stored in memory S1 is a picture that occurs in personal experiences. 


\section{Conclusion}

Based on the research finding, it is concluded that the critical thinking process through four stages is gathering information, evaluates of information, making solution, and evaluates the conclusions. But experiencing the error of selecting information caused in the processing of information S1 experiencing misunderstanding and recall the semantic memory. And S1 conducts critical thinking process through four stages: gathering information, evaluates of information, making solution, and evaluates the conclusions is complete but experiencing divided attention in setting assumption.

\section{References}

[1]. Beyer, B.K. 1987.Critical thinking: What is it? "Social Education," 49, 270-276

[2]. Beyer, Barry K. (1985). Critical Thinking. Phi Delta Kappa, 408 N. Union, P.O. Box 789, Bloomington, IN $47402-0789$.

[3]. Ennis, R. H. 1985. "Goals for a Critical Thinking Curriculum". Costa, A. L. (ed). 1988.Developing Minds: A Resource Book For Teaching Thinking. Virginia: ASCD Fisher, Alec.2007. Critical Thinking: An Introduction. Jakarta: Erland

[4]. Gagne, M. Robert. 1970. The Conditions of Learning, United States of American

[5]. Hong, K. S. \& Jacob, S.M. (2012). Critical Thinking and Socratic Questioning in Asynchronous Mathematics Discussion Forums. Malaysian Journal of Educational Technology, 12 (3), pp. 17-26.

[6]. Marzano, R. J. 2001. Designing a new taxonomy of educational objectives. Thousand Oaks, CA: Corwin Press.

[7]. Muhfahroyin. 2009. Empowering Critical Thinking Skills.Disses from http://muhfahroyin.blogspot.com accessed April 9, 2013.

[8]. Polya, G .. 2004. How to Solve It's a new aspect of mathematical method: Pricenton University Press

[9]. S. M. Jacob and H. K. Sam (2008). Critical Thinking Skills in Online Mathematics.

[10]. Discussion Forums and Mathematical Achievement: Swinburne University of Technology, Sarawak Campus Malaysia.

[11]. Slavin, Robert E.2006.Psikologi Pendidikan Theory and Praktik.Jakarta: Index

[12]. Solso, R. L., Maclin, M. K., \& Maclin, O. H. 2008.Cognitive Psychology Eighth Edition. United States of America: Pearson

Sutini. "Identification of Critical Thinking Process in Solving Mathematic Problems." IOSR Journal of Research \& Method in Education (IOSR-JRME) 7.4 (2017): 05-10. 